\title{
The growth pattern of transplanted normal and nodular hepatocytes
}

\author{
Silvia Doratiotto - Petra Krause • Maria Paola Serra • \\ Fabio Marongiu - Marcella Sini - Sarah Koenig • \\ Ezio Laconi
}

Accepted: 15 April 2011/Published online: 29 April 2011

(C) The Author(s) 2011. This article is published with open access at Springerlink.com

\begin{abstract}
Overt neoplasia is often the end result of a long biological process beginning with the appearance of focal lesions of altered tissue morphology. While the putative clonal nature of focal lesions has often been emphasized, increasing attention is being devoted to the possible role of an altered growth pattern in the evolution of carcinogenesis. Here we compare the growth patterns of normal and nodular hepatocytes in a transplantation system that allows their selective clonal proliferation in vivo. Rats were pre-treated with retrorsine, which blocks the growth of resident hepatocytes, and were then transplanted with hepatocytes isolated from either normal liver or hepatocyte nodules. Both cell types were able to proliferate extensively in the recipient liver, as expected. However, their growth pattern was remarkably different. Clusters of normal hepatocytes integrated in the host liver, displaying a normal histology; however, transplanted nodular hepatocytes formed new hepatocyte nodules, with altered morphology and sharp demarcation from surrounding host liver. Both the expression and distribution of proteins involved in cell polarity, cell communication, and cell adhesion, including connexin 32, E-cadherin, and matrix metalloproteinase-2, were altered in clusters of nodular hepatocytes. Furthermore, we
\end{abstract}

S. Doratiotto and P. Krause contributed equally to this work.

S. Doratiotto - M. P. Serra · F. Marongiu · M. Sini ·

E. Laconi $(\bowtie)$

Department of Biomedical Sciences and Biotechnology,

Section of Experimental Pathology, University of Cagliari,

Via Porcell, 4, 09125 Cagliari, Italy

e-mail: elaconi@unica.it

P. Krause $\cdot$ S. Koenig

Department of General Surgery, University Medical Centre

Goettingen, Göttingen, Germany were able to show that down-regulation of connexin 32 and E-cadherin in nodular hepatocyte clusters was independent of growth rate. These results support the concept that a dominant pathway towards neoplastic disease in several organs involves defect(s) in tissue pattern formation.

Keywords Liver nodules - Growth pattern · Cell transplantation $\cdot$ Focal growth

\section{Introduction}

Many human solid cancers, including hepatocellular carcinoma, often arise from discrete focal lesions that long precede the overt clinical appearance of the disease. In fact, it is well established that such lesions represent a common precursor site for overt neoplasia (Clark et al. 1984; Foulds 1975; Hruban et al. 2000; Hytiroglou et al. 2007; Montironi et al. 2002; Noffsinger 2009; Schreer and Lüttges 2005; Su et al. 1997), thus implying that gaining insights into their biology and pathogenesis bears direct relevance to our understanding of the natural history of neoplastic disease.

Historically, the salient feature of cancer precursor lesions has been considered to reside in their putative clonal nature, and this notion still forms the basis for most of the current theories on the pathogenesis of neoplastic disease (Diallo et al. 2001; Garcia et al. 2000; Iannaccone et al. 1987; Mason et al. 2010). Within this perspective, research efforts continue to be focussed mainly on putative biochemical and molecular changes of rare altered cells that could possibly explain their selective growth, resulting in the emergence of focal proliferative lesions (Hanahan and Weinberg 2000).

However, over the past few years increasing attention has been devoted to the analysis of the phenotypic property 
that serves to define these focal lesions, i.e. their altered growth pattern. In fact, a nodule, an adenoma, a polyp or a papilloma are defined as discrete lesions displaying a morphology distinct from that of the normal surrounding counterpart. While this phenotypic feature has long been neglected and implicitly considered as a mere by-product of clonal growth, it is now emerging as a fundamental property of pre-cancerous lesions with specific pathogenetic relevance to the process (Chen et al. 2009; Doratiotto et al. 2009; Schmeichel et al. 1998).

Over the past several years, we have developed a model of orthotopic hepatocyte transplantation wherein the selective clonal expansion of both normal and nodular hepatocytes can be achieved and analysed over time in an in vivo system (Laconi and Laconi 2002). This transplantation model is based on a pre-conditioning regimen, i.e. exposure of the recipient animal to retrorsine (RS), a naturally occurring alkaloid that induces a persistent block on the endogenous hepatocyte cell cycle (Laconi et al. 1999). It was observed that both normal and nodular hepatocytes undergo clonal proliferation when injected into the liver of RS-treated hosts. However, the biological outcome is radically different in either case. In fact, transplanted normal hepatocytes integrate in the host liver and gradually repopulate the entire organ with a seemingly normal histology (Laconi et al. 2001b). In contrast, when hepatocytes isolated from liver nodules are injected into RS-treated animals, they also proliferate but fail to integrate in the host parenchyma and rather undergo expansive growth, reforming liver nodules that rapidly progress to hepatocellular carcinoma (Laconi et al. 2001a).

Thus, this system offers the unique opportunity to compare two clonally expanding cell populations, normal and nodular hepatocytes, in vivo and possibly to dissect the biochemical and/or molecular alterations critically relevant to their different phenotypic behaviour (Marongiu et al. 2008). In the present study, we analysed the growth pattern of transplanted normal and nodular hepatocytes vis-à-vis the expression of proteins involved in cell polarity, cell migration, cell-to-cell and cell-to-extracellular matrix adhesion, and communication, including connexin 32 (Cx32), E-cadherin, and matrix metalloproteinase-2 (MMP-2). We observed that the altered growth pattern of transplanted nodular hepatocytes is consistently associated with decreased expression of Cx32, E-cadherin, and MMP-2. Furthermore, it was unequivocally found that these alterations are inherent to nodular lesions and are unrelated to growth per se.

\section{Materials and methods}

All animals were maintained on daily cycles of alternating $12 \mathrm{~h}$ light/darkness with food and water available ad libitum. They were fed Purina Rodent Lab Chow diet (Ditta Mucedola, Italy) throughout the experiment and received humane care in accordance with the regulations and criteria of the Animal Care Unit of the University of Cagliari.

\section{Induction of liver nodules in donor rats and isolation of nodular and normal hepatocytes}

Hepatocyte nodules were induced according to a wellcharacterized experimental model in the rat, as previously described (Laconi et al. 2001b) and nodule-bearing livers were perfused according to a standard two-step collagenase perfusion technique (Laconi et al. 2001a; Seglen 1976). Large ( $>5 \mathrm{~mm}$ in diameter) nodules were physically separated from surrounding tissue and cells isolated from nodular tissue were suspended in Williams E culture medium (Sigma, cat No. W-4125) and prepared for transplantation experiments. Cell viability, determined by trypan blue dye exclusion, was $80-85 \%$. Normal hepatocytes were isolated from a normal young adult syngeneic Fischer 344 donor rat following a similar two-step collagenase perfusion technique. The isolated cell fraction used for transplantation studies was judged to be $\sim 95 \%$ hepatocytes by morphological analysis and cell viability was consistently $>85 \%$, as determined by trypan blue dye exclusion. Aliquots of these cells were also used for PCR analysis of MMP-2 RNA expression (see the following paragraphs).

\section{Treatment of recipient rats and transplantation of hepatocytes}

In order to follow the fate of donor hepatocytes in the recipient liver, the dipeptidyl-peptidase type IV-deficient (DPPIV $^{-}$) rat model was used (Thompson et al. 1991). In this system, cells isolated from a Fischer 344 rat expressing DPPIV $\left(\right.$ DPPIV $\left.^{+}\right)$are transplanted into a syngeneic DPPIV $^{-}$recipient, such that cells derived from donors may be detected in the host liver through simple (immuno-) histochemical techniques. A colony of DPPIV ${ }^{-}$F344 rats has been established in the Department of Biomedical Sciences and Technology, University of Cagliari. DPPIV ${ }^{-}$ recipient rats were treated according to the RS-based protocol developed in our laboratories (Laconi and Laconi 2002). Briefly, 24 DPPIV $^{-}$rats, with a body mass of 80-100 g, were given two injections of RS (from Sigma), $30 \mathrm{mg} / \mathrm{kg}$ each, i.p., 2 weeks apart. Two weeks after the last injection, animals were divided into two groups (A and $\mathrm{B}$, of 12 animals each) and were infused with either cells isolated from $\mathrm{DPPIV}^{+}$hepatocyte nodules (groups A,) or 
cells isolated from DPPIV ${ }^{+}$normal liver donor (groups B). Cells were isolated as described above and were delivered via portal vein infusion, suspended in $0.3 \mathrm{ml}$ of Williams $\mathrm{E}$ medium. Animals from the two groups were killed 1 month after transplantation (Tx); livers were excised, cut into 1-2 mm thick slices and grossly examined for the presence of hepatic nodules and/or any other visible lesions. Liver samples taken from each liver were either fixed in $10 \%$ buffered formaldehyde for standard histological analysis (H\&E staining) or snap frozen. Histochemical determination of DPPIV enzyme activity was performed as described (Laconi et al. 2001b).

Immunohistochemistry for Ki67, Cx32, and E-cadherin was performed using specific monoclonal antibodies (antiKi67 from Abcam, cat \# 16667; anti-Cx32 from Zymed Labs, cat \# 34-5700, anti-E-cadherin from Santa Cruz, cat. \# sc-8426). Detection of primary antibodies was accomplished using the avidin/biotin peroxidase system (Vectastain ABC kit; Vector Laboratories, Burlingame, CA).

\section{Colocalization of DPPIV with Cx32 and MMP-2}

Tissues were immunostained for the first antigen [antiCx32 (1:5,000) and anti-MMP-2 (1:100)] (Neomarkers Asbach, Germany) using Alexa 488 conjugated goat antirabbit or anti-mouse IgG (Molecular Probes Goettingen, Germany) for fluorescence detection (1:400, $1 \mathrm{~h}$ at RT) and then further processed with the second immunostaining protocol. After rehydration in Tris buffer, specimens were blocked and subsequently incubated with the second primary antibody (anti-DPPIV, 1:100), rinsed with Tris buffer and exposed to the second Alexa Fluor 568 goat antimouse IgG2a (Molecular Probes Goettingen, Germany) (1:400, $1 \mathrm{~h}$ at RT). Slides were finally covered with Vectashield ${ }^{\circledR}$ mounting medium with DAPI $(1 \mu \mathrm{l} / \mathrm{ml})$ (Vector Laboratories, UK) to visualise cell nuclei. Negative controls were carried out for each antibody by omitting the primary antibody from the protocol. Multiple immunofluorescence-labelled specimens were serially excited and observed with the TEXAS Red-, FITC- and UV-filter set on an inverted confocal microscope (LEICA DM IRE2, Bensheim, Germany). Pictures of each filter set were digitally merged using layering technology software (Leica FW 4000, Version 1.1).

\section{RNA isolation and RT-PCR}

Total RNA was isolated using TRIzol reagent (Invitrogen, Carlsbad, CA) according to the manufacturer's protocol. RNA integrity and purity were confirmed by $1 \%$ agarose gel electrophoresis and OD260/OD280 $\mathrm{nm}$ absorption ratio
$>1.8$. Two grams of DNase-I treated RNA of each sample were reverse-transcribed using Promega reagents (Promega, Madison, WI). The resulting cDNA was analysed by PCR using the following primers and conditions: $\beta 2$-microglobulin (FWD: $5^{\prime}$-GTCGTGCTTGCCATTC AGA-3'; REV: $5^{\prime}$-TGAAGAAGATGGTGTGCTCA- $3^{\prime} ; T_{\mathrm{a}}$ : $48^{\circ} \mathrm{C}$; 30 cycles); MMP-2 (FWD: $5^{\prime}$-TCCAGGAGCTCT ATGGGCCCTC-3'; REV: 5'- GCAGCCCAGCCAGTCC GATT- $3^{\prime} ; T_{\mathrm{a}}: 63^{\circ} \mathrm{C} ; 40$ cycles). PCR thermal profile was as follows: $95^{\circ} \mathrm{C}$ for $2 \mathrm{~min}$, then $95^{\circ} \mathrm{C}$ for $30 \mathrm{~s}, T_{\mathrm{a}}$ for $1 \mathrm{~min}$, $72^{\circ} \mathrm{C}$ for $1 \mathrm{~min}$ for an appropriate number of cycles, followed by extension at $72^{\circ} \mathrm{C}$ for $5 \mathrm{~min}$. PCR products were visualized by $2 \%$ agarose gel electrophoresis.

\section{Results}

The growth pattern of normal and nodular hepatocytes

Normal transplanted hepatocytes integrated well in the recipient liver, forming clusters of irregular shape which were macroscopically indistinguishable in the context of the host tissue. No signs of compression of the surrounding tissue were evident during the growth of normal cells derived from donors. The distribution of DPPIV enzyme activity displayed the typical chicken-wire pattern, consistent with its normal bile canalicular location (Fig. 1a, c).

However, the growth pattern of transplanted nodular hepatocytes was remarkably different. These cells formed focal lesions that were readily identifiable as greyishbrown areas on macroscopic examination, ranging in size from $<1$ to $3 \mathrm{~mm}$ in diameter, both on the liver surface and on sectioning. These lesions were mostly round or oval in shape and were sharply demarcated from the surrounding host tissue (Fig. 1b, d). The latter displayed signs of compression, as indicated by the presence of concentric hepatocyte plates distributed around larger nodules (Fig. 1f). Moreover, histochemical detection of DPPIV confirmed the altered polarity of nodular hepatocytes, with no defined pattern in the protein enzyme distribution (Fig. 1b, d). Many cells in nodules expressed cytoplasmic DPPIV activity with relatively scarce membrane localization, which became even more evident on immunofluorescence examination (Fig. 1d).

The surface receptor CD44, which is normally found in non-parenchymal liver cells and is up-regulated in different types of cancers, including hepatocellular carcinoma (Yang et al. 2010), was not expressed by nodular hepatocyte clusters derived from transplanted cells (Fig. 1g, h). However, scattered CD44-positive cells were present both inside nodules and in surrounding liver exposed to RS (Fig. 1h), as already reported in the literature (Kon et al. 2009). 
Fig. 1 Histochemical staining for DPPIV enzyme activity (orange-rust) in clusters of normal (a) and nodular

(b) hepatocytes transplanted into the liver of DPPIVdeficient host rats pre-treated with RS. Immunofluorescence labelling for DPPIV expression (red) in clusters of normal (c) and nodular (d) hepatocytes transplanted as above; DAPI (blue) identifies nuclei. Both enzyme activity and protein distribution were typically associated with the cell membrane in normal hepatocyte clusters $(\mathbf{a}, \mathbf{c})$, while they were irregular and diffuse to the cytoplasm in the expanding clusters of nodular hepatocytes $(\mathbf{b}, \mathbf{d})$. e, $\mathbf{f}$ Two serial cryostat sections of a nodular hepatocyte cluster stained for DPPIV expression (e, orange-rust) and with standard H\&E (f). Note the presence of megalocytes in the RS-treated surrounding liver (upper-left). g, h Two serial sections of a large nodular hepatocyte cluster stained for DPPIV (g) and for the presence of CD44 marker (h); CD44positive non-parenchymal cells are present inside the nodule, while transplanted nodular hepatocytes are negative
Normal hepatocyte Tx
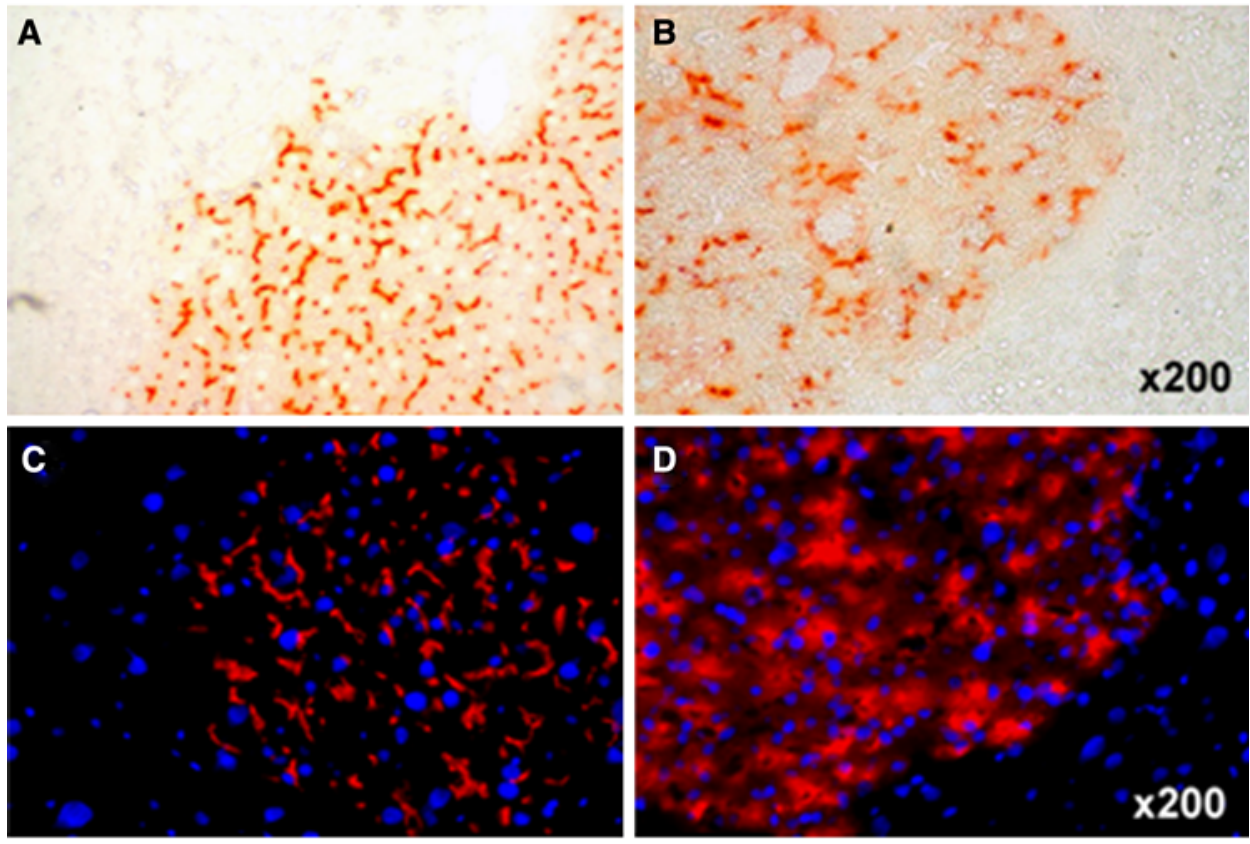

Nodular hepatocyte Tx
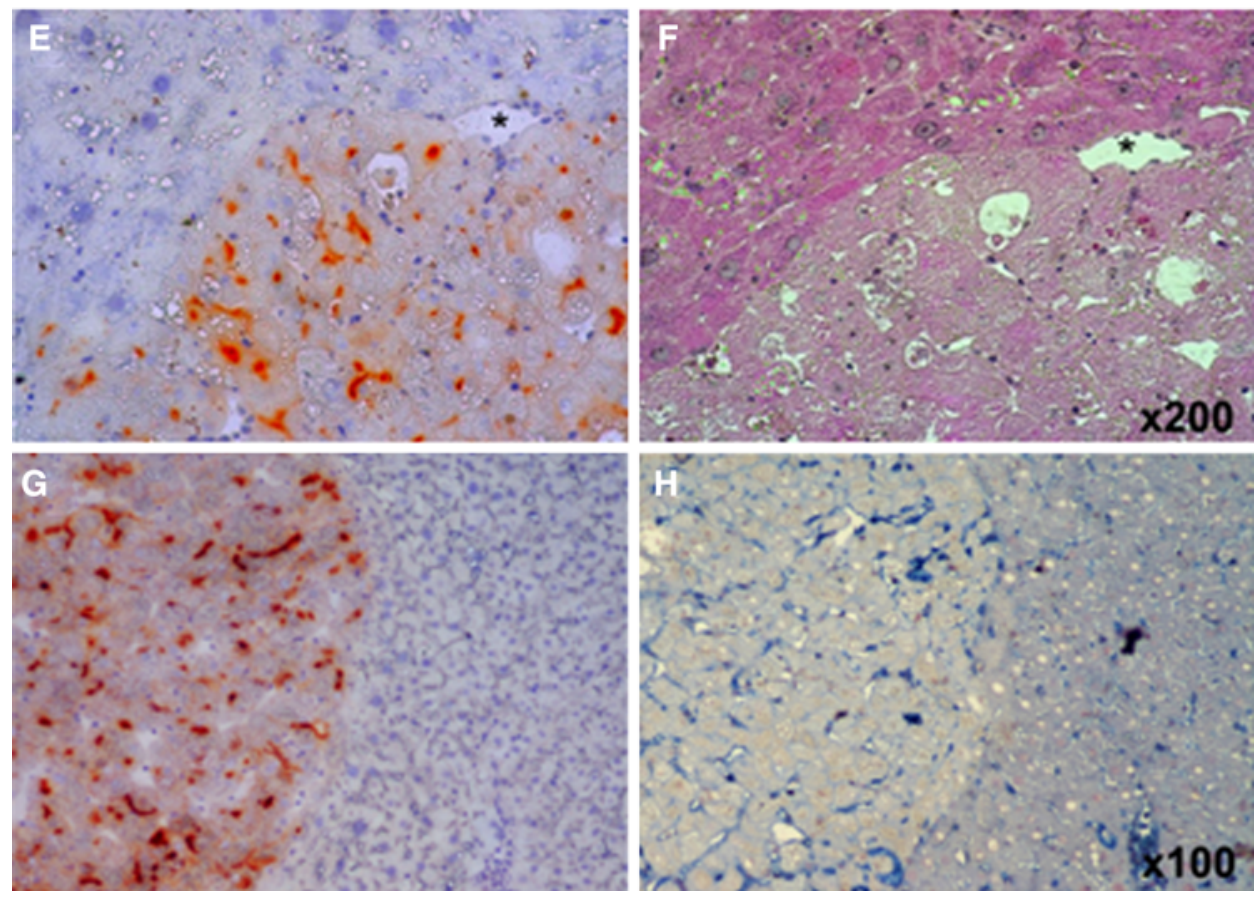

The expression of Cx32 in transplanted normal and nodular hepatocytes

Connexins are the major proteins of gap junctions, which serve to establish communication channels between adjacent cells. As such, they are involved in both tissue pattern formation and maintenance of integrated cellular functions. Small molecules $(<1 \mathrm{kDa}$ in size) can be exchanged through gap junctions, thereby contributing to the functional cooperation of cells within tissues (Vinken et al. 2008). Given their direct involvement in processes related to tissue pattern formation and cell-to-cell communication, we decided to compare the expression of $\mathrm{Cx} 32$, the major gap junction protein present in the liver, in the expanding clusters of normal and nodular transplanted hepatocytes.

As presented in Fig. 2, Cx32 was regularly found with the typical punctuated pattern of distribution at the cell membrane in small and larger clusters of transplanted 

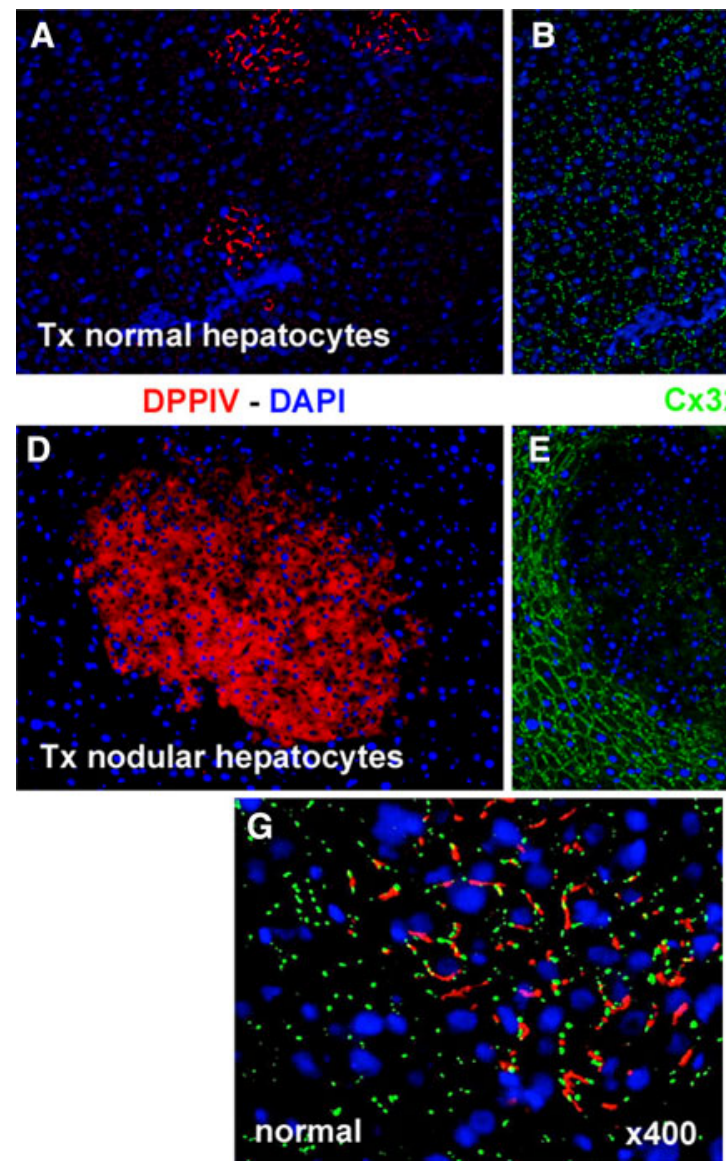

Fig. 2 Immunofluorescence colocalization of DPPIV (red) and Cx32 (green) in clusters of normal $(\mathbf{a}, \mathbf{b}, \mathbf{c}, \mathbf{g})$ and nodular $(\mathbf{d}, \mathbf{e}, \mathbf{f}$, h) hepatocytes. a, d DPPIV only; b, e Cx32 staining only; c, f, g, $\mathbf{h}$ staining for DPPIV and Cx32 were merged. Note the regular pattern

normal hepatocytes (Fig. 2a-c, g). However, in nodular hepatocyte clusters resulting from the transplantation of isolated nodular cells, the expression of $\mathrm{Cx} 32$ was nearly absent or greatly reduced (Fig. 2d-f, h).

Furthermore, low Cx32 levels were found in nodules with high or low proliferative rates, as indicated by Ki67 labelling ranging from $2 \%$ (Fig. 3b) to $34 \%$ (Fig. 3f). In contrast, clusters of normal transplanted hepatocytes with high or low Ki67 labelling displayed a normal pattern of Cx32 expression, comparable to or even higher than that of the surrounding host tissue (Fig. 3g-h). No correlation could therefore be established between Cx32 expression and proliferative activity in nodular hepatocyte clusters.

The expression of E-cadherin in transplanted normal and nodular hepatocytes

Another protein critically involved in the genesis and maintenance of tissue architecture in the liver is E-cadherin. Cadherins constitute a superfamily of at least 80

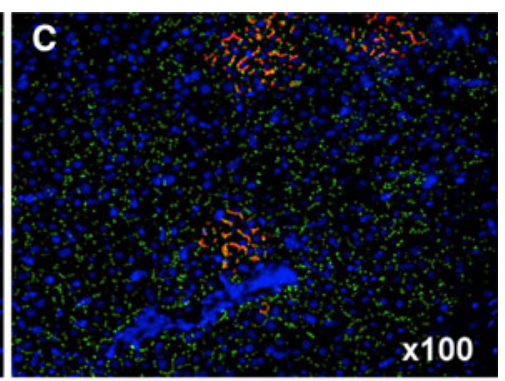

Merged DPPIV - C 32 - DAPI
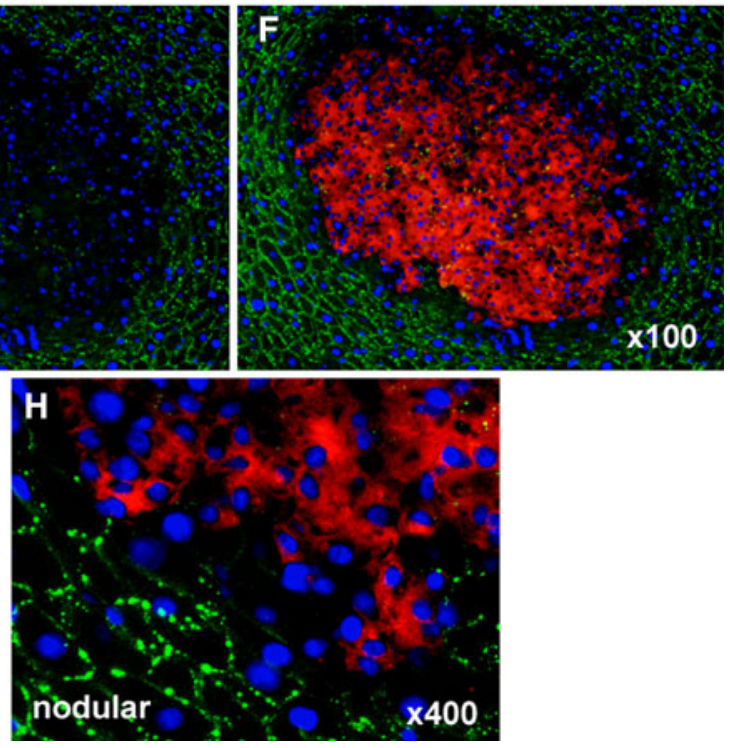

of expression of Cx32 in normal hepatocyte clusters $(\mathbf{b}, \mathbf{c}, \mathbf{g})$, while the gap junction protein is almost undetected in the donor-derived nodular lesion $(\mathbf{e}, \mathbf{f}, \mathbf{h})$. See "Materials and methods" for details

members and are a major component of adherens junction, i.e. the zipper-like seals between adjacent cells. Cadherin-catenin complexes are also at the crossroad of cell signalling coupled with cell adhesion (van Roy and Berx 2008). The epithelial E-cadherin is expressed in the normal liver and is under dynamic regulation during liver regeneration following partial hepatectomy (Monga et al. 2001). In the present study, our aim was to compare the levels of expression of E-cadherin in the expanding clusters of transplanted normal and nodular hepatocytes, in light of the phenotypic differences in their growth pattern described above. The results obtained are illustrated in Fig. 4. Clusters of transplanted normal hepatocytes displayed a regular distribution of E-cadherin in the cell membrane (Fig. 4a-d). However, such regular distribution was completely abrogated in nodular hepatocyte clusters (Fig. 4e-h). In fact, the latter displayed an overall decrease and patchy staining of the cell adhesion protein, in line with the altered morphology of nodular lesions. 
Fig. 3 Pairs of serial sections stained for immunohistochemical detection of Cx32 (left panels, a, c, e, $\mathbf{g}$, punctuated blue spots) or Ki67 (right panels, $\mathbf{b}, \mathbf{d}, \mathbf{f}, \mathbf{h}$, intense blue nuclei). b, d, $\mathbf{f}, \mathbf{g}$,

h Processed for DPPIV enzyme activity. Note that different rates of Ki67 labelling in nodular hepatocyte clusters (b: $2 \%, \mathbf{d}$ : $11 \%$, f: $34 \%$ ), are associated with similar low levels of $\mathrm{Cx} 32$ expression (a, c, e). However, significant Ki67 labelling in normal hepatocyte clusters (h) is paired with normal distribution of Cx32 gap junction protein $(\mathbf{g})$. See "Materials and methods" for details
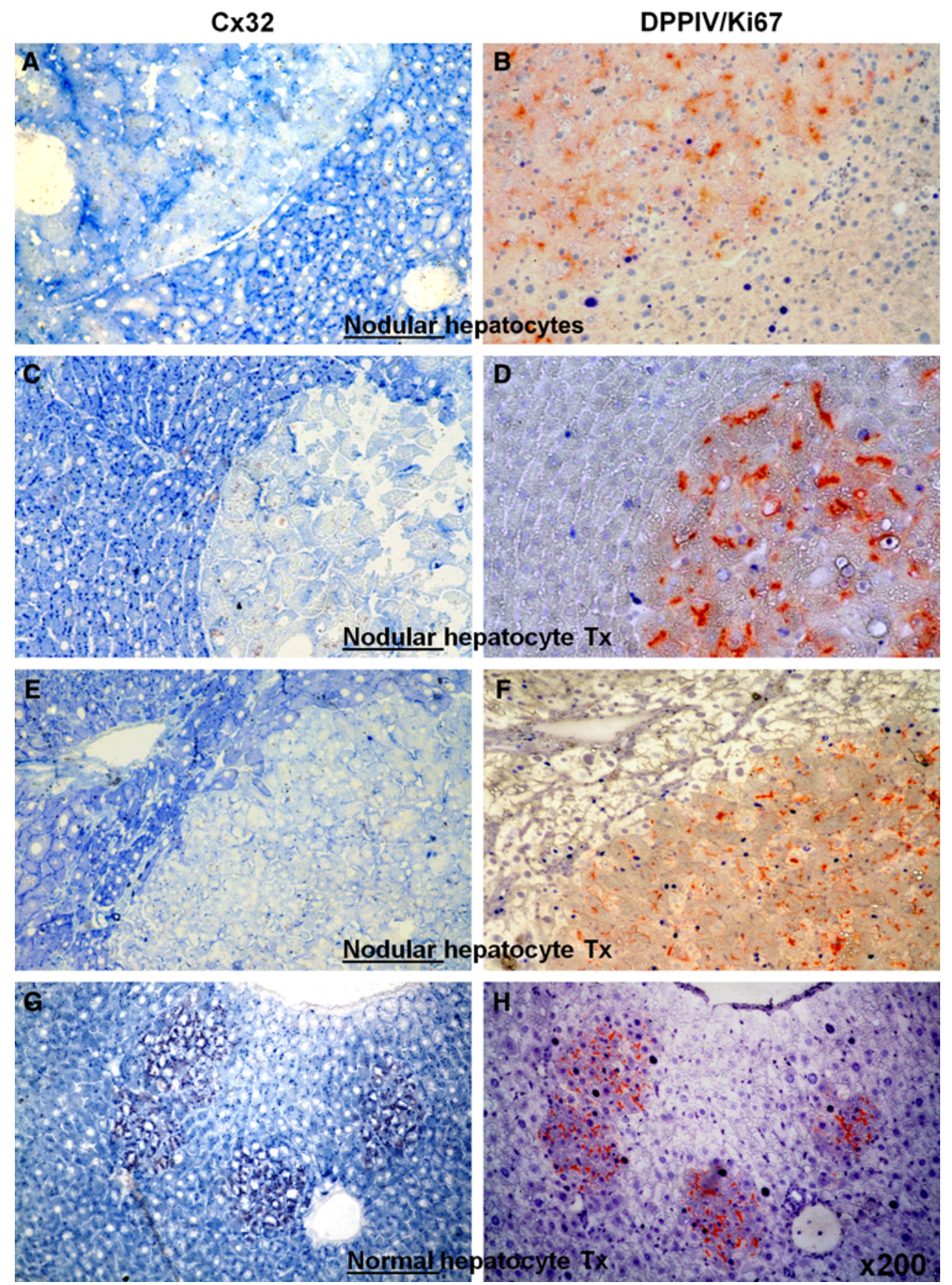

The expression of MMP-2 in transplanted normal and nodular hepatocytes

Matrix metalloproteinases (MMPs) are a family of enzymes that can collectively degrade all components of the extracellular matrix. They play fundamental roles in several processes, including tissue remodelling, inflammation, wound healing, fibrosis, cell migration, and metastasis, among others (Ellerbroek and Stack 1999). MMPs are synthesized as pro-enzymes and are activated upon proteolytic cleavage in the extracellular space (Montironi et al. 2002).
MMP-2, also known as gelatinase A, can degrade collagens, gelatin, elastin, fibronectin, laminins, and is possibly involved in the activation of other MMPs, such as MMP-9 and MMP-13 (Fridman et al. 2009). In a previous study, it was found that MMP-2 is expressed at the leading edge of expanding clusters of transplanted normal hepatocytes (Koenig et al. 2005). Given the postulated role of MMP-2 in cell migration, we decided to analyse the pattern of distribution of this enzyme in the expanding clusters of normal and nodular cell populations. As illustrated in Fig. 5, a positive immunofluorescent signal corresponding to MMP-2 
Fig. 4 Pairs of serial sections stained for immunohistochemical detection of E-Cadherin (left panels, a, c, e, g) or DPPIV enzyme activity (right panels, b, d, f, h). c, d, $\mathbf{g}$, $\mathbf{h}$ Magnifications of $\mathbf{a}, \mathbf{b}, \mathbf{e}, \mathbf{f}$, respectively. While E-cadherin expression was regularly found (punctuated dark blue dots, arrows) in clusters of transplanted normal hepatocytes (compare a vs. b and $\mathbf{c}$ vs. $\mathbf{d}$, dotted lines), immunostaining in nodular hepatocyte clusters was virtually undetected (compare e vs. $\mathbf{f}$ and $\mathbf{g}$ vs. $\mathbf{h}$ ), while arrows in $\mathbf{g}$ indicate punctuated expression of the protein in the liver surrounding nodular hepatocytes. See "Materials and methods" for details
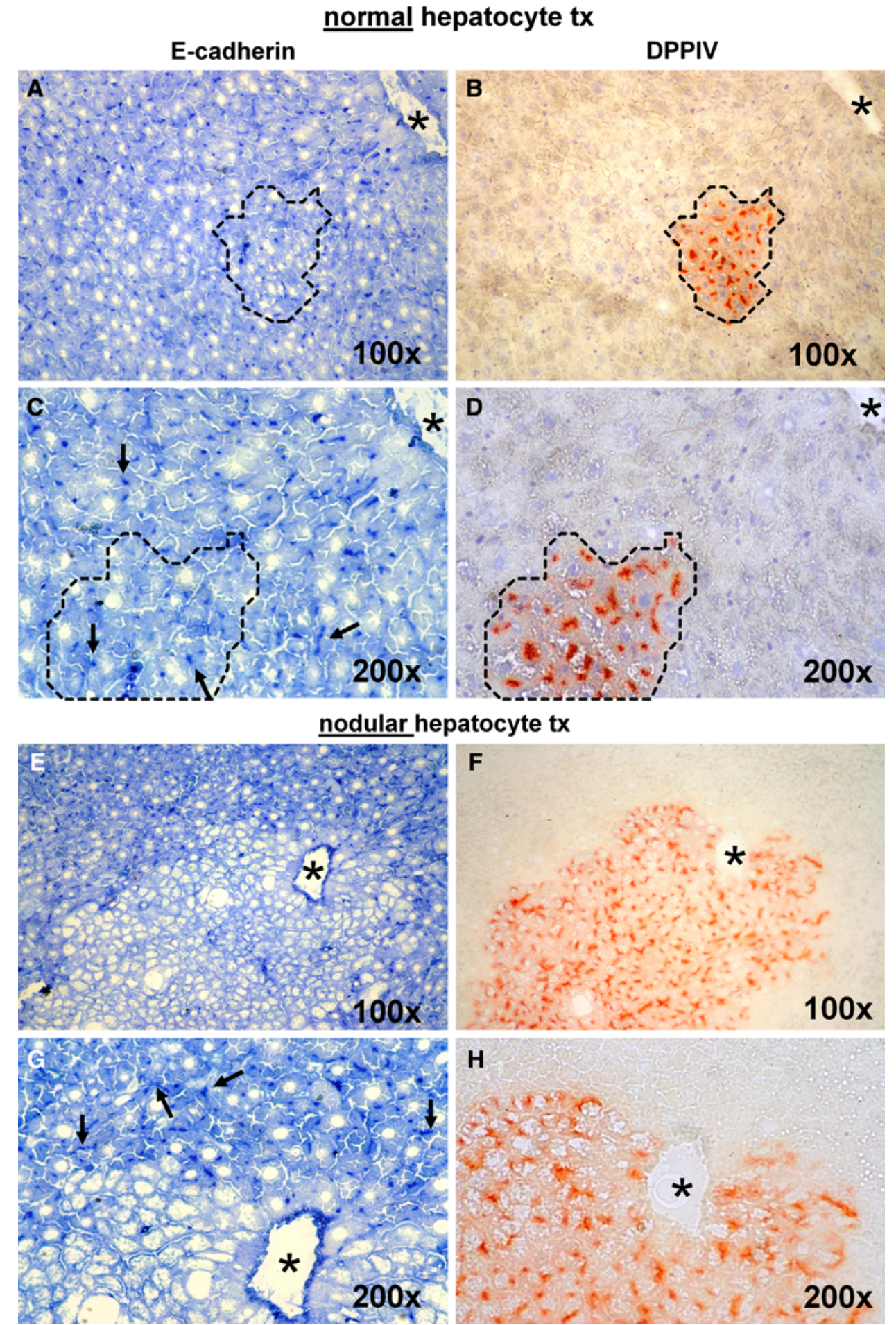

was found at the ill-defined boundary between clusters of normal transplanted hepatocytes and the surrounding host liver (Fig. 5a-c), in agreement with previous findings (Koenig et al. 2005). In addition, scattered MMP-2 activity could also be detected within these clusters (Fig. $5 \mathrm{~g}$ ). On the other hand, a sharp demarcation was readily apparent between clusters of transplanted nodular hepatocytes and the positive immunostaining for MMP-2 (Fig. 5d-f). While the protein was strongly expressed in the tissue surrounding nodular lesions, MMP-2 activity was virtually absent within nodular hepatocyte clusters (Fig. 5h).

Furthermore, we found that the expression of MMP-2 RNA was markedly decreased in nodular hepatocyte preparations as compared to their normal counterparts (Fig. 6). 


\section{Discussion}

In this study, we compare the growth pattern and the expression of proteins involved in cell adhesion, to cell-tocell communication and cell migration in two different populations of clonally expanding hepatocytes: namely, hepatocytes isolated from a normal untreated liver and hepatocytes isolated from carcinogen-induced liver nodules. In a former study, we already observed that neither cell type was able to proliferate to any significant extent upon transplantation into syngeneic, untreated normal hosts (Laconi et al. 2001a). However, both normal and nodular hepatocytes underwent selective clonal expansion following injection into the liver of rats pre-treated with RS. Furthermore, we observed that the biological outcome was radically different following transplantation of either cell type in RS-treated recipients, as expected (Laconi et al. 2001a, b). In fact, the selective proliferation of normal transplanted hepatocytes resulted in liver repopulation, reproducing a seemingly normal tissue architecture, with

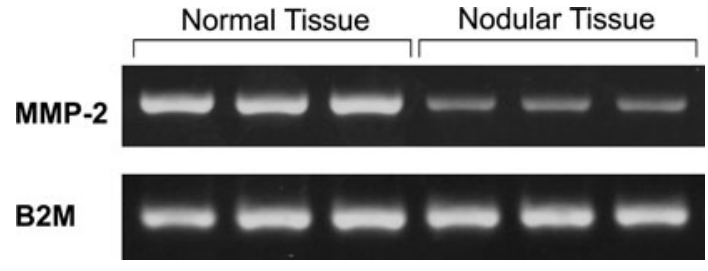

Fig. 6 Expression of MMP-2 RNA in normal and nodular hepatocyte preparations. Triplicates of both cell preparations were processed. A marked reduction in gene expression is evident in nodular cells (upper lanes); in the lower lanes the expression of the beta-2microglobulin gene is presented for comparison. The experiment was repeated twice with similar pattern of results. See "Materials and methods" for details

no evidence of pre-neoplastic and/or neoplastic lesions (Laconi et al. 2001b). In contrast, the transplantation of nodular hepatocytes was consistently associated with their failure to integrate in the host liver and the formation of liver nodules. Moreover, such nodules had the potential to progress to hepatocellular carcinoma (Laconi et al. 2001a), as also confirmed in this study (data not presented).

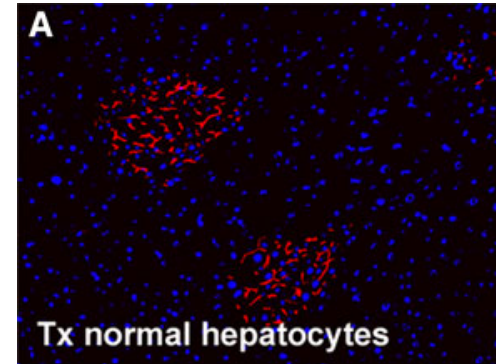

DPPIV - DAPI
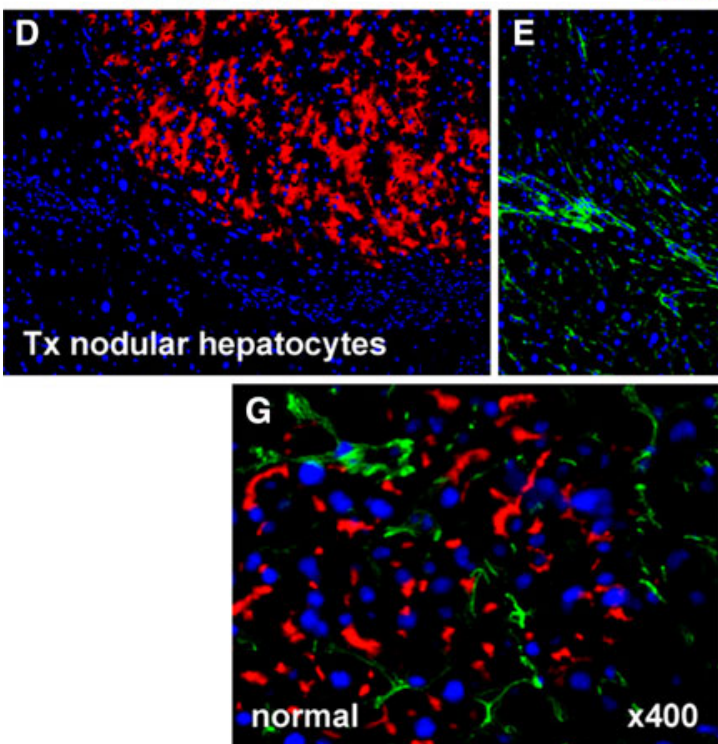

Fig. 5 Immunofluorescence colocalization of DPPIV (red) and MMP-2 (green) in clusters of normal $(\mathbf{a}, \mathbf{b}, \mathbf{c}, \mathbf{g})$ and nodular $(\mathbf{d}, \mathbf{e}$, f, h). Normal hepatocyte clusters display decreased fluorescence staining for MMP-2 compared to surrounding host liver $(\mathbf{a}-\mathbf{c})$.
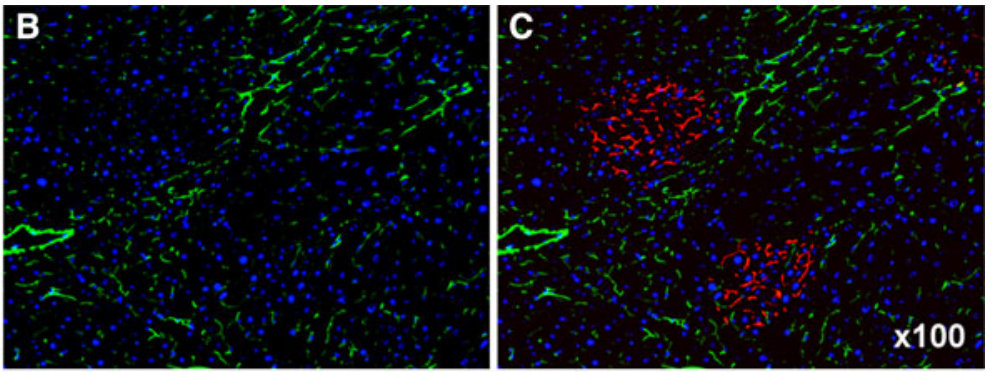

Merged DPPIV - MMP2 - DAPI
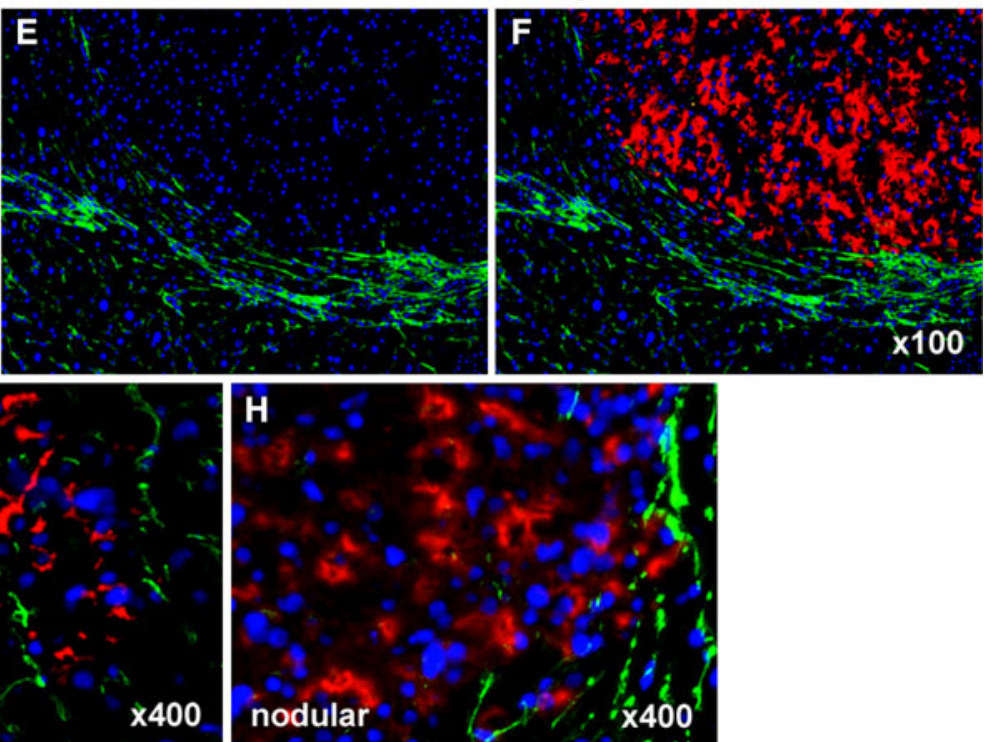

However, low levels of expression are detected (g). In contrast, no MMP-2 protein is detectable inside nodular hepatocyte clusters, while intense expression is noted in the surrounding liver $(\mathbf{d}, \mathbf{e}, \mathbf{f}, \mathbf{h})$. See "Materials and methods" for details 
Given these background findings, we performed a study on the growth pattern of normal and nodular hepatocytes transplanted into RS-treated host rats, taking advantage of the fact that we could compare two rapidly expanding cell populations under similar experimental conditions. As expected, both cell types exhibited selective clonal proliferation in the recipient liver. The distribution of DPPIV enzyme activity was remarkably altered in nodular hepatocyte clusters, as shown in Fig. 1. Aberrant expression of this enzyme has been reported in different types of cancers, including hepatocellular carcinoma (Stecca et al. 1997). It is reasonable to hypothesize that the altered distribution of DPPIV enzyme activity in the expanding nodular hepatocytes may reflect, at least in part, an altered polarity of these cells. On the other hand, DPPIV has also been proposed as a possible marker for early diagnosis of HCC in hepatitis C virus-positive cirrhotic patients (Archer et al. 2009).

Low levels of Cx32 expression have long been reported in early focal lesions developing during liver carcinogenesis in the rat (Krutovskikh et al. 1991). However, this alteration was found to be reversibly associated with the proliferative rate of individual foci (Neveu et al. 1994). Furthermore, normal proliferating hepatocytes also express Cx32 to a low extent (Kren et al. 1993; Yamamoto et al. 2005), questioning whether altered expression of this protein is a primary phenomenon in some nodular lesions or it is rather a consequence of their increased growth rate (Neveu et al. 1994). Our results provide unequivocal evidence indicating that decreased Cx32 expression is in fact an inherent property of nodular hepatocyte lesions, at least under the experimental conditions of the present studies. Clusters of clonally expanding normal hepatocytes, with a Ki67 labelling index comparable to that of transplanted nodular clusters, displayed normal levels of $\mathrm{Cx} 32$ protein, while Cx32 expression was low in nodular lesions originating from transplanted cells, regardless of high or low proliferative rate (Fig. 3).

A similar pattern of results was visible on analysis of the expression of E-cadherin. While expanding clusters of normal transplanted hepatocytes displayed a regular distribution of this membrane protein, focal lesions resulting from transplantation of nodular hepatocytes demonstrated low levels and altered localization of E-cadherin. Studies on the expression of E-cadherin in human hepatocellular carcinoma (HCC) have generated rather conflicting results. Earlier reports described elevated levels of E-cadherin in the majority of thin-trabecular HCC (Ihara et al. 1996). More recently, decreased expression of E-cadherin was included in a panel of 12 molecular alterations that significantly discriminate between dysplastic nodules and early human HCC (Llovet et al. 2006). Consistent with the latter finding, E-cadherin has also been proposed as a marker in the differential diagnosis between adenoma and
HCC (Tretiakova et al. 2009). Importantly, our results provide direct evidence that these alterations appear early in the process and are independent of cell proliferation per se. Thus, it is possible that the failure of nodular hepatocytes to integrate into the surrounding parenchyma is due, at least in part, to the altered expression of proteins involved in cell-to-cell communication and adhesion. Such alterations could involve different pathways. E-cadherin is part of a multifunctional scaffolding complex playing a key role in establishing cell polarity in several tissues (Cai and Mostov 2009). This complex includes proteins such as IQGAP2 and Cdc42. Interestingly, both IQGAP2-deficient and Cdc42-deficient mice are highly prone to developing HCC (Schmidt et al. 2008; van Hengel et al. 2008), thereby suggesting that alterations in tissue pattern formation are mechanistically linked to the pathogenesis of neoplastic disease.

We also analysed the expression of MMP-2 following transplantation of either normal or nodular hepatocyte in RS-treated animals. It was found that this enzyme was mostly expressed at the leading edge of normal hepatocyte clones, as already reported (Koenig et al. 2005), although scattered activity could also be detected within DPPIVpositive clusters. However, the pattern of MMP-2 expression was different in relation to nodular hepatocyte clusters. A sharp demarcation could be observed between the expression of MMP-2 protein and expanding nodular lesion. While the enzyme was expressed in liver tissue surrounding nodules, virtually no MMP-2 protein could be detected within such lesions. In addition, a markedly decreased expression of MMP-2 RNA was present in nodular hepatocytes as compared to normal counterparts. As already mentioned, MMPs are a family of enzymes that collectively play fundamental roles in several processes involved in neoplastic progression, including cell migration and metastasis (Ellerbroek and Stack 1999). MMPs exist in the matrix as pro-enzymes and are activated upon proteolytic cleavage. Unlike other MMPs, the activation of MMP-2 occurs at the cell surface (Montironi et al. 2002), a feature which confers to this enzyme a central role in cell migration. It requires the binding of membrane type 1 MMPs (MT1-MMPs) with the tissue inhibitor of metalloproteinase type 2 (TIMP2) (Lehti et al. 1998; Nagase et al. 2006). Native MMP-2 then binds to this complex and this favours its proteolytic activation by a second MT1-MMP molecule on the cell membrane. The activity of MMPs is increased during tumour progression and is associated with invasion and metastases (Ellerbroek and Stack 1999). Our findings indicating low MMP-2 expression in early nodular lesions are therefore difficult to reconcile with the proposed role of MMPs in the evolution of neoplastic disease. However, it is important to point out that early hepatic nodules do not display any signs of invasive capacity and they are sharply 
demarcated from the surrounding tissue. If indeed MMP-2 activity is essential to hepatocyte migration, then its low expression within nodular hepatocytes might help in explaining their inability to crawl in between surrounding hepatocytes and their lack of integration into the host liver, thereby giving rise to proliferative focal lesions.

In summary, the present study compares the fate of normal and nodular hepatocytes following orthotopic transplantation into syngeneic host liver pre-conditioned with RS. Both cell types underwent selective clonal expansion, as expected, indicating that growth per se was not a distinguishing feature between the two cell populations. However, their growth pattern and biological fates were remarkably different, and this was associated with altered expression of DPPIV, Cx32, E-cadherin, and MMP-2 proteins, markers associated with cell polarity, cell-to-cell communication, cell adhesion, and cell migration. We interpret these findings as supporting the concept of a dominant biological pathway leading to neoplastic disease involving defect(s) in tissue pattern formation (Feigin and Muthuswamy 2009; Wang 2009; Wodarz and Näthke 2007). Several molecular alterations, other than the ones described in these studies, are likely to result in a similar phenotype.

Acknowledgments This work was supported by AIRC (Italian Association for Cancer Research, grant No. 4927 and 10604 to EL). We thank Anna Saba and Giovanna Porqueddu for their excellent technical and secretarial assistance.

Open Access This article is distributed under the terms of the Creative Commons Attribution Noncommercial License which permits any noncommercial use, distribution, and reproduction in any medium, provided the original author(s) and source are credited.

\section{References}

Archer KJ, Mas VR, David K, Maluf DG, Bornstein K, Fisher RA (2009) Identifying genes for establishing a multigenic test for hepatocellular carcinoma surveillance in hepatitis $\mathrm{C}$ viruspositive cirrhotic patients. Cancer Epidemiol Biomarkers Prev 18:2929-2932

Cai L, Mostov K (2009) Polarity is destiny. Cell 139:660-662

Chen A, Cuevas I, Kenny PA, Miyake H, Mace K, Ghajar C, Boudreau A, Bissell M, Boudreau N (2009) Endothelial cell migration and vascular endothelial growth factor expression are the result of loss of breast tissue polarity. Cancer Res 69: 6721-6729

Clark WR Jr, Elder DE, Guerry D 4th, Epstein MN, Greene MH, Van Horn M (1984) A study of tumor progression: the precursor lesions of superficial spreading and nodular melanoma. Hum Pathol 15:1147-1165

Diallo R, Schaefer KL, Poremba C, Shivazi N, Willmann V, Buerger H, Dockhorn-Dworniczak B, Boecker W (2001) Monoclonality in normal epithelium and in hyperplastic and neoplastic lesions of the breast. J Pathol 193:27-32

Doratiotto S, Marongiu F, Faedda S, Pani P, Laconi E (2009) Altered growth pattern, not altered growth per se, is the hallmark of early lesions preceding cancer development. Histol Histopathol 24: 101-106

Ellerbroek SM, Stack MS (1999) Membrane associated matrix metalloproteinases in metastasis. Bioessays 21:940-949

Feigin ME, Muthuswamy SK (2009) Polarity proteins regulate mammalian cell-cell junctions and cancer pathogenesis. Curr Opin Cell Biol 21:694-700

Foulds L (1975) Neoplastic Development, vol 2. Academic Press, New York, pp 1-15

Fridman R, Toth M, Peña D, Mobashery S (2009) Activation of progelatinase B (MMP-9) by gelatinase A (MMP-2). Cancer Res 55:2548-2555

Garcia SB, Novelli M, Wright NA (2000) The clonal origin and clonal evolution of epithelial tumours. Int $\mathrm{J}$ Exp Pathol 81:89-116

Hanahan D, Weinberg RA (2000) The hallmarks of cancer. Cell 100:57-70

Hruban RH, Goggins M, Parsons J, Kern SE (2000) Progression model for pancreatic cancer. Clin Cancer Res 6:2969-2972

Hytiroglou P, Park Y, Krinsky G, Theise ND (2007) Hepatic precancerous lesions and small hepatocellular carcinoma. Gastroenterol Clin North Am 36:867-887

Iannaccone PM, Weinberg WC, Deamant FD (1987) On the clonal origin of tumors: a review of experimental models. Int J Cancer 39:778-784

Ihara A, Koizumi H, Hashizume R, Uchikoshi T (1996) Expression of epithelial cadherin and alpha- and beta-catenins in nontumoral livers and hepatocellular carcinomas. Hepatology 23:1441-1447

Koenig S, Stoesser C, Krause P, Becker H, Markus PM (2005) Liver repopulation after hepatocellular transplantation: integration and interaction of transplanted hepatocytes in the host. Cell Transplant 14:31-40

Kon J, Ichinohe N, Ooe H, Chen Q, Sasaki K, Mitaka T (2009) Thy1positive cells have bipotential ability to differentiate into hepatocytes and biliary epithelial cells in galactosamine-induced rat liver regeneration. Am J Pathol 175:2362-2371

Kren BT, Kumar NM, Wang SQ, Gilula NB, Steer CJ (1993) Differential regulation of multiple gap junction transcripts and proteins during rat liver regeneration. J Cell Biol 123:707-718

Krutovskikh VA, Oyamada M, Yamasaki H (1991) Sequential changes of gap-junctional intercellular communications during multistage rat liver carcinogenesis: direct measurement of communication in vivo. Carcinogenesis 12:1701-1706

Laconi S, Laconi E (2002) Principles of hepatocyte transplantation. Semin Cell Dev Biol 13:433-438

Laconi S, Curreli F, Diana S, Pasciu D, De Filippo G, Sarma DSR, Pani P, Laconi E (1999) Liver regeneration in response to partial hepatectomy in rats treated with retrorsine: a kinetic study. J Hepatol 31:1069-1074

Laconi S, Pani P, Pillai S, Pasciu D, Sarma DSR, Laconi E (2001a) A growth constrained environment drives tumor progression in vivo. Proc Natl Acad Sci USA 98:7806-7811

Laconi S, Pillai S, Porcu PP, Shafritz DA, Pani P, Laconi E (2001b) Massive liver replacement by transplanted hepatocytes in the absence of exogenous growth stimuli in rats treated with retrorsine. Am J Pathol 158:771-777

Lehti K, Lohi J, Valtanen H, Keski-Oja J (1998) Proteolytic processing of membrane-type-1 matrix metalloproteinase is associated with gelatinase A activation at the cell surface. Biochem J 334(Pt 2):345-353

Llovet JM, Chen Y, Wurmbach E, Roayaie S, Fiel MI, Schwartz M, Thung SN, Khitrov G, Zhang W, Villanueva A, Battiston C, Mazzaferro V, Bruix J, Waxman S, Friedman SL (2006) A molecular signature to discriminate dysplastic nodules from early hepatocellular carcinoma in HCV cirrhosis. Gastroenterology 131:1758-1767 
Marongiu F, Doratiotto S, Montisci S, Pani P, Laconi E (2008) Liver repopulation and carcinogenesis: two sides of the same coin? Am J Pathol 172:857-864

Mason WS, Liu C, Aldrich CE, Litwin S, Yeh MM (2010) Clonal expansion of normal-appearing human hepatocytes during chronic hepatitis B virus infection. J Virol 84:8308-8315

Monga SP, Pediaditakis P, Mule K, Stolz DB, Michalopoulos GK (2001) Changes in WNT/beta-catenin pathway during regulated growth in rat liver regeneration. Hepatology 33:1098-1109

Montironi R, Mazzucchelli R, Scarpelli M (2002) Precancerous lesions and conditions of the prostate: from morphological and biological characterization to chemoprevention. Ann N Y Acad Sci 963:169-184

Nagase H, Visse R, Murphy G (2006) Structure and function of matrix metalloproteinases and TIMPs. Cardiovasc Res 69:562-573

Neveu MJ, Hully JR, Babcock KL, Hertzberg EL, Nicholson BJ, Paul DL, Pitot HC (1994) Multiple mechanisms are responsible for altered expression of gap junction genes during oncogenesis in rat liver. J Cell Sci 107(Pt 1):83-95

Noffsinger AE (2009) Serrated polyps and colorectal cancer: new pathway to malignancy. Annu Rev Pathol 4:343-364

Schmeichel KL, Weaver VM, Bissell MJ (1998) Structural cues from the tissue microenvironment are essential determinants of the human mammary epithelial cell phenotype. J Mammary Gland Biol Neoplasia 3:201-213

Schmidt VA, Chiariello CS, Capilla E, Miller F, Bahou WF (2008) Development of hepatocellular carcinoma in Iqgap2-deficient mice is IQGAP1 dependent. Mol Cell Biol 28:1489-1502

Schreer I, Lüttges J (2005) Precursor lesions of invasive breast cancer. Eur J Radiol 54:62-71

Seglen PO (1976) Preparation of isolated rat liver cells. Methods Cell Biol 13:29-83

Stecca BA, Nardo B, Chieco P, Mazziotti A, Bolondi L, Cavallari A (1997) Aberrant dipeptidyl peptidase IV (DPP IV/CD26) expression in human hepatocellular carcinoma. J Hepatol 27: $337-345$
Su Q, Benner A, Hofmann WJ, Otto G, Pichlmayr R, Bannasch P (1997) Human hepatic preneoplasia: phenotypes and proliferation kinetics of foci and nodules of altered hepatocytes and their relationship to liver cell dysplasia. Virchows Arch 431:391-406

Thompson NL, Hixson DC, Callanan H, Panzica M, Flanagan D, Faria RA, Hong W, Hartel-Schenk S, Doyle DA (1991) Fischer rat substrain deficient in dipeptidyl peptidase IV activity makes normal steady-state RNA level and an altered protein: use as a liver-cell transplantation model. Biochem J 273:497-502

Tretiakova MS, Hart J, Shabani-Rad MT, Zhang J, Gao ZH (2009) Distinction of hepatocellular adenoma from hepatocellular carcinoma with and without cirrhosis using E-cadherin and matrix metalloproteinase immunohistochemistry. Mod Pathol 22:1113-1120

van Hengel J, D’Hooge P, Hooghe B, Wu X, Libbrecht L, De Vos R, Quondamatteo F, Klempt M, Brakebusch C, van Roy F (2008) Continuous cell injury promotes hepatic tumorigenesis in cdc42deficient mouse liver. Gastroenterology 134:781-792

van Roy F, Berx G (2008) The cell-cell adhesion molecule E-cadherin. Cell Mol Life Sci 65:3756-3788

Vinken M, Henkens T, De Rop E, Fraczek J, Vanhaecke T, Rogiers V (2008) Biology and pathobiology of gap junctional channels in hepatocytes. Hepatology 47:1077-1088

Wang Y (2009) Wnt/Planar cell polarity signaling: a new paradigm for cancer therapy. Mol Cancer Ther 8:2103-2109

Wodarz A, Näthke I (2007) Cell polarity in development and cancer. Nat Cell Biol 9:1016-1024

Yamamoto T, Kojima T, Murata M, Takano K, Go M, Hatakeyama N, Chiba H, Sawada N (2005) p38 MAP-kinase regulates function of gap and tight junctions during regeneration of rat hepatocytes. J Hepatol 42:707-718

Yang XR, Xu Y, Yu B, Zhou J, Qiu SJ, Shi GM, Zhang BH, Wu WZ, Shi YH, Wu B, Yang GH, Ji Y, Fan J (2010) High expression levels of putative hepatic stem/progenitor cell biomarkers related to tumour angiogenesis and poor prognosis of hepatocellular carcinoma. Gut 59:953-962 